\title{
Risk Factors for Postoperative Complications after Percutaneous Nephrolithotomy
}

Robin Bahadur Basnet, ${ }^{1}$ Anil Shrestha, ${ }^{1}$ Parash Mani Shrestha, ${ }^{1}$ Bishwa Raj Joshi ${ }^{1}$

${ }^{1}$ Department of Urology, National Academy of Medical Sciences Bir Hospital, Kathmandu, Nepal.

\begin{abstract}
Background:To identify the perioperative factors associated with complications after percutaneous nephrolithotomy by classification of complications according to the modified Clavien scoring system and evaluation of the minor and major complications related to the procedure.

Methods: A prospective study of all the percutaneous nephrolithotomy performed by standard technique within 1.5 years at Bir Hospital was made. Possible demographic, preoperative and intraoperative variables were included in the study and patients were followed up postoperatively for any complications. All complications were classified according to modified Clavien scoring system and analyzed to identify the prognostic variables.

Results: Two hundred and forty six percutaneous nephrolithotomy done within the study period were analyzed. Although $41.06 \%$ of the study population developed complications, only $9.35 \%$ had major complications. Age, body mass index, gender, clinical presentation, history of previous surgery and ASA score did not correlate with complications. Diabetes was the only comorbidity associated $(\mathrm{p}=0.0482)$. Preoperatively estimated stone burden $(\mathrm{p}$ $=0.0023)$, number of calyces involved by the stones $(\mathrm{p}=0.0002)$, and presence of staghorn calculi were significantly associated with development of postoperative complications. Multiple tracts were required $(p=0.0151)$ and operative time was longer $(\mathrm{p}<0001)$ in the patients who developed complications.

Conclusions: Percutaneous nephrolithotomy has lesser complications. Diabetic patients are more prone to develop complications. Larger stone burden, involvement of multiple calyces by stones and staghorn calculi are associated with need of multiple tracts and longer operative time, thus predisposing to higher incidence of complications.

Keywords: Clavien score; complications; percutaneous; nephrolithotomy.
\end{abstract}

\section{INTRODUCTION}

Since its first description in 1976, percutaneous nephrolithotomy (PCNL) has become the surgery of choice for renal stones $2 \mathrm{~cm}$ or larger. ${ }^{1}$ With stone-free rates ranging from $75 \%$ to $95 \%$, PCNL has proven to be an efficacious treatment for large calculi, staghorn, stones in kidneys with abnormal anatomy, and stones in more complicated patient groups. ${ }^{2-6}$ Despite the advantages, incidence of complications is reported from $16 \%$ to $83 \%$, with major complications representing $4.7 \%$ in tertiary referral centers. ${ }^{3,4,7-10}$

The Clavien classification is widely used in grading surgical complications. This system was modified in $2004^{11}$ to increase its accuracy and applicability. Recent studies have extended the use of the modified Clavien classification system to the assessment of outcomes of PCNL; and has been formally validated with categorization of PCNL specific complications..$^{12-14}$

We present the results of PCNL with the aim to determine the preoperative and perioperative prognostic factors of complications associated with PCNL.

\section{METHODS}

After ethical clearance for the study from the subject committee of department of urology and institutional review board, a prospective observational study of all patients who underwent PCNL at Bir hospital of Kathmandu, Nepal, was undertaken from August 2015 to January 2017. Informed consents for the study were taken from all patients.

All patients were assessed preoperatively and records of demographic parameters, medical history including those of recurrent urinary tract infections, hematuria, 
pain, medical comorbidities were made. In addition to routine investigations; $\mathrm{CT}$ urography, along with stone density measured in unenhanced film, were done for all the patients. Staghorn stone was defined in the study as stone in the pelvis with branches extending to all three poles and partial staghorn as pelvic stone with branches extending to calyces in one or two polar calyces.

PCNL were performed under General or Spinal Anaesthesia. Six French ureteral catheter were placed in ipsilateral pelvicalyceal system by cystoscopy or ureteroscopy in lithotomy position under fluroscopic guidance in the beginning. All PCNL done in prone position, transpapillary puncture made with help of fluoroscopic guidance using 18 gauze two-part needle after retrograde opacifiation of the pelvicaliceal system via the ureteral catheter were only included in the study. The tract dilatation and number were either by single shot technique or serial telescopic dilatation and single or multiple tracts respectively. Nephroscopy were done with a 21 French rigid nephroscope. Large stones were fragmented with pneumatic lithotripter. Small stones and fragments were removed either by continuous normal saline irrigation using a pump or removed with forceps. The exit strategies were total tubeless, tubeless or standard. Intraoperative variables studied included operative time and number and location of the tracts.

Postoperatively, patients were managed with intravenous fluids, antibiotics and analgesics. They were discharged when clinically stable. The patients were routinely followed up at 2 weeks with an X-ray and ultrasound of KUB and those who were not stone free were followed up again at 4 weeks of operation.

Any complications during this period were classified by the modified Clavien Score for PCNL. Complications classified as Clavien 3a, 3b, 4a, 4b and 5 were categorized as major complications. ${ }^{9}$ In cases where patients had more than one complication, only the highest Clavien score were included. Final analysis was done for patients fulfilling all the inclusion criteria.

\section{RESULTS}

During the study period, a total of 289 PCNL were performed by two consultant urologists. Two hundred and forty six patients fulfilled the inclusion criteria and 43 patients had to be excluded due to various reasons as shown in table 1.

The demographic variables studied and the outcomes have been summarized in table 2 . The mean age of the cohort was 37.56 years and the mean BMI was $25.08 \mathrm{Kg}$ / $\mathrm{m}^{2}$. Male population made up $60.17 \%$ of the cohort. The most common presentation was pain in the abdomen or flank, in $59.76 \%$. Fifty six patients had undergone surgery on the ipsilateral side in the past; $13 \%$ with history of open surgery and $4.88 \%$ with history of PCNL.

\section{Table 1. PCNL Performed during the study period.}

\begin{tabular}{lr} 
Total & 289 \\
\hline Fulfilling the inclusion criteria & 246 \\
Excluded & 43 \\
Age below 14 years & 4 \\
No preoperative CT scan available & 5 \\
Bilateral Procedures & 1 \\
Supine Position & 3 \\
Conversion to Open Procedure & 1 \\
Ureteric Calculus & 4 \\
Not reporting with X-ray KUB at 2 and 4 & 5 \\
weeks & \\
$\begin{array}{l}\text { Non pneumatic stone fragmentation (Laser, } \\
\text { ultrasonic) }\end{array}$ & 20
\end{tabular}

Full staghorn calculus were present in $7.32 \%$ and partial staghorn were present in $19.92 \%$. The average number of calyces involved was 1.3. The mean stone burden, calculated from non enhanced CT scan as size of an ellipsoid, was $411.26 \mathrm{~mm}^{2}$, and mean stone density of $1051.58 \mathrm{HU}$. Renal anomalies such as horse shoe kidney and ectopic kidney and collecting system anomalies such as bifid pelvis was present in $6.5 \%$ of the cohort.

Single upper pole access, either supracostal or infracostal, to the kidney was chosen in $15.45 \%$ and $30.08 \%$ of PCNL were done with multiple tracts. The mean operative time, i.e. time from the first puncture to exit, was 45.54 minutes, ranging from 15 minutes to 125 minutes. The mean post operative hospital stay was 3.38 days.

As summarized in table 4 , a total of 101 , i.e. $41.06 \%$ had some postoperative complications, with $9.35 \%$ developing major complications. The most common complication was postoperative fever.

The relation of different variables to outcome is briefly summarized in table 2. Age, BMI, gender, clinical presentation, history of previous surgery and ASA score did not significantly correlate with complications. Diabetes was significantly related with development of complications, with $75 \%$ of diabetic cohorts developing some form of complication, most common being postoperative fever. Among the stone characteristics, the preoperatively estimated stone burden $(p=0.0023)$, number of calyces involved by the stones $(p=0.0002)$, and presence of staghorn calculi were significantly associated with development of postoperative 
complications. Similarly, multiple tracts $(p=0.0151)$ and longer operative time $(p<0.001)$ was needed in the patients bound to develop complications.

Bleeding was the most common major complication. Out of 7 patients $(2.84 \%)$ who required blood transfusion, only one had solitary stone and PCNL was done through a single tract. Three patients (1.22\%) in the entire cohort underwent angioembolisation for development of pseudoaneurysm. Seven (2.84\%) patients required placement of intercostal drains for chest complications. One patient had colonic perforation and managed with controlled colocutaneous fistula. We had no patients requiring ICU care, nor were there any mortality.

Table 2. Demographic Variables and outcome.

\begin{tabular}{lrrrr} 
Variables & Cohort & $\begin{array}{r}\text { No Complications } \\
145(58.94 \%)\end{array}$ & $\begin{array}{r}\text { Complications } \\
101(41.06 \%)\end{array}$ & $\begin{array}{r}\text { Significance } \\
\text { P }\end{array}$ \\
\hline Age (Mean \pm SD) & $37.56 \pm 14.02$ & $38.71 \pm 12.60$ & $41.10 \pm 13.92$ & 0.1623 \\
BMI (Mean \pm SD) & $25.08 \pm 12.51$ & $23.83 \pm 14.29$ & $26.32 \pm 11.54$ & 0.1478 \\
Gender & $148(60.16 \%)$ & $91(62.76 \%)$ & $57(56.44 \%)$ & 0.3202 \\
Male (\%) & $98(39.84 \%)$ & $54(37.24 \%)$ & $44(43.56 \%)$ & 0.3202 \\
Female (\%) & & & & \\
\hline
\end{tabular}

Clinical (preoperative)

Pain (\%)

Hematuria (\%)

UTI (\%)

Comorbidities

Hypertension (\%)

Diabetes (\%)

Other/more than one (\%)

History of previous surgery

\begin{tabular}{|c|c|c|c|c|}
\hline Open & $32(13.01 \%)$ & $18(12.41 \%)$ & $14(13.86 \%)$ & 0.7399 \\
\hline PCNL & $12(4.88 \%)$ & $6(4.14 \%)$ & 6 (5.94\%) & 0.5200 \\
\hline SWL & 6 (2.44\%) & $4(2.76 \%)$ & $2(1.98 \%)$ & 0.6971 \\
\hline URSL & $6(2.44 \%)$ & $5(3.45 \%)$ & 1 (0.99\%) & 0.7744 \\
\hline \multicolumn{5}{|l|}{ ASA Score } \\
\hline 1 & 142 (57.72\%) & 89 (61.38\%) & $53(52.47 \%)$ & 0.1649 \\
\hline 2 & 92 (37.40\%) & 54 (37.24\%) & $38(37.62 \%)$ & 0.9518 \\
\hline 3 & $12(4.88 \%)$ & $6(4.14 \%)$ & $6(3.96 \%)$ & 0.9441 \\
\hline
\end{tabular}

147 (59.75\%)

$21(8.5 \%)$

45 (18.29\%)

41 (5.69\%)

32 (13.01\%)

$8(3.25 \%)$

$4(2.76 \%)$

89 (61.38\%)

$58(57.43 \%)$

0.5351

$10(6.90 \%)$

$11(10.89 \%)$

0.2716

24 (16.55\%)

$21(20.79 \%)$

0.3984

5 (17.24\%)

16 (15.84\%)

0.7724

8 (7.92\%)

0.0482

$4(3.96 \%)$

0.6025

Table 3. Stone Characteristics, Intraoperative variables and outcome.

\begin{tabular}{lrrrr} 
Variables & Cohort & $\begin{array}{r}\text { No Complications } \\
145(58.94 \%)\end{array}$ & $\begin{array}{r}\text { Complications } \\
101(41.06 \%)\end{array}$ & $\begin{array}{r}\text { Significance } \\
p\end{array}$ \\
\hline Laterality & & & & \\
$\quad$ Left & $131(53.25 \%)$ & $74(51.03 \%)$ & $57(56.44 \%)$ & 0.4038 \\
$\quad$ Right & $115(46.75 \%)$ & $63(43.44 \%)$ & $52(51.48 \%)$ & 0.2147 \\
\hline Stone Burden in $\mathrm{mm}^{2}$ (Mean \pm SD) & $411.26 \pm 128.32$ & $302.25 \pm 221.02$ & $402.97 \pm 291.23$ & 0.0023 \\
\hline Number of Calyces Involved (Mean) & $1.3 \pm 0.73$ & $1.4 \pm 0.8$ & $1.8 \pm 0.86$ & 0.0002 \\
\hline Stone Density (HU) (Mean \pm SD) & $1051.58 \pm 233.832$ & $1066.38 \pm 216.99$ & $1018.61 \pm 274.56$ & 0.1294
\end{tabular}




\begin{tabular}{lrrrr} 
Location of the stone & & & \\
$\quad$ Pelvic & $64(26.02 \%)$ & $39(26.90 \%)$ & $25(24.75 \%)$ & 0.7059 \\
$\quad$ Upper pole & $15(6.10 \%)$ & $8(5.51 \%)$ & $7(6.93 \%)$ & 0.6476 \\
$\quad 7(2.85 \%)$ & $4(2.76 \%)$ & $3(2.97 \%)$ & 0.9225 \\
$\quad$ Mid pole & $56(22.76 \%)$ & $29(20.00 \%)$ & $27(26.73 \%)$ & 0.2165 \\
$\quad$ Lower pole & $104(42.28 \%)$ & $58(40.00 \%)$ & $46(45.54 \%)$ & 0.3878 \\
\hline Multiple & $18(7.32 \%)$ & $6(4.14 \%)$ & $12(11.88 \%)$ & 0.0221 \\
\hline Partial Staghorn & $49(19.92 \%)$ & $17(11.72 \%)$ & $32(31.68 \%)$ & 0.0001 \\
\hline Multiple tracts & $74(30.08 \%)$ & $35(24.14 \%)$ & $39(38.61 \%)$ & 0.0151 \\
\hline Upper pole tract & $38(15.45 \%)$ & $18(12.41 \%)$ & $20(19.80 \%)$ & 0.1153 \\
\hline Urinary tract anomaly & $16(6.5 \%)$ & $12(8.27 \%)$ & $4(3.96 \%)$ & 0.1783 \\
\hline Operative time & $45.54 \pm 20.42$ & $38.75 \pm 17.64$ & $70.77 \pm 14.26$ & $<0.001$ \\
\hline Hospital Stay & $3.38 \pm 1.28$ & $3.28 \pm 0.91$ & $3.48 \pm 1.83$ & 0.2591 \\
\hline
\end{tabular}

Table 4. Complications classified according to modified Clavien score.

\begin{tabular}{lrr} 
Clavien Score & Number & Percentage \\
\hline 1 & 56 & $55.44 \%$ \\
\hline 2 & 22 & $21.78 \%$ \\
\hline $3 a$ & 20 & $19.80 \%$ \\
\hline $3 b$ & 3 & $2.97 \%$ \\
\hline $4 a$ & 0 & $0 \%$ \\
\hline 5 & 0 & $0 \%$ \\
\hline 5 & 0 & $0 \%$ \\
\hline
\end{tabular}

The patients with complications were taken as a new cohort and the significant variables in table 2 and 3 were further analyzed to establish the factors responsible for major complications, and have been summarized in table 5. Among them, presence of full staghorn calculi $(p=0.0264)$, partial staghorn $(p=0.0092)$ multiple tracts made for stone removal $(p<0.0001)$ and longer operation time $(p=0.0067)$ were significantly correlated with development of major complications .

Table 5. Assessment of risk factors for major complications.

\begin{tabular}{lrrr} 
Variables & Any Complications & Major Complications & Significance \\
Diabetes $(\%)$ & $101(41.06 \%)$ & $23(9.35 \%)$ & 0.8991 \\
\hline Stone Size in $\mathrm{mm}^{2}$ (Mean \pm SD) & $8(7.9 \%)$ & $415.07 \pm 351.41$ & 0.8630 \\
Number of Calyces Involved (Mean) & $402.97 \pm 291.23$ & $1.48 \pm 0.65$ & 0.0962 \\
\hline Full Staghorn & $1.8 \pm 0.86$ & $7(30.43 \%)$ & 0.0264 \\
Partial staghorn & $12(11.88 \%)$ & $14(60.86 \%)$ & 0.0092 \\
\hline Multiple tracts & $32(31.68 \%)$ & $21(91.30 \%)$ & $<0.0001$ \\
\hline Operative time & $39(38.61 \%)$ & $60.87 \pm 20.39$ & 0.0067 \\
\hline
\end{tabular}

\section{DISCUSSION}

PCNL is a safe and reliable technique for the treatment of renal stones, which has replaced open surgery as the treatment of choice for large or multiple renal calculi. PCNL is an invasive procedure with reported complication rate of up to $83 \%{ }^{10}$ and major complication rates of about $4.7 \%$ in tertiary referral centers. $3,4,7-10$ Although our study population had a complication rate of $41.06 \%$ and major complication of $9.35 \%$, all of them could be managed with minimal further medical or surgical intervention. No patients required intensive care service and there were no mortalities.

The presence of comorbidity has been reported to increase the risk of complications during or after PCNL. Major complications after PCNL have been reported to be more common in patients with diabetes mellitus. ${ }^{15}$ Among the patients with comorbidities, only diabetes had a higher chance of complications in our study. PCNL is considered safe in patients with history of renal surgery on ipsilateral side. ${ }^{16,17}$ This was also reflected in our study.

Higher stone burden and presence of staghorn calculi have been identified as risk factors for need of multiple tracts, increase in operative time and incomplete stone clearance and complications in many series. ${ }^{18-20}$ This was also seen in our study, with more number of febrile episodes, bleeding and chest complications occurring in these population. Laterality, stone density and calyceal location of stones were not significantly associated with complications. 
The study was conducted in a single center in a short period of time. Further studies taking into account both high and low volume centers; and also general and specialist centers with multiple observers are recommended for better validation of the results.

\section{CONCLUSIONS}

PCNL has lesser complications. Diabetic patients are more prone to develop complications. Larger stone burden, involvement of multiple calyces by stones and staghorn calculi are associated with need of multiple tracts and longer operative time, thus predisposing to higher incidence of complications.

\section{REFERENCES}

1. Assimos D, Krambeck A, Miller NL, Monga M, Murad $\mathrm{MH}$, Nelson CP, et al. Surgical Management of Stones: American Urological Association/Endourological Society Guideline, PART II. J Urol. 2016;196:1161-69.[PubMed]

2. Segura JW, Patterson DE, LeRoy AJ, Williams HJ Jr, Barrett DM, Benson RC Jr, et al. Percutaneous removal of kidney stones: Review of 1,000 cases. J Urol. 1985; 134:1077-1081.[PubMed]

3. Rudnick DM, Stoller ML. Complications of percutaneous nephrostolithotomy. Can J Urol. 1999;6:872-875. [PubMed]

4. Tomaszewski JJ, Smaldone MC, Schuster T, Jackman SV, Averch TD. Factors affecting blood loss during percutaneous nephrolithotomy using balloon dilation in a large contemporary series. J Endourol. 2010; 24(2): 207211.[PubMed]

5. Violette PD1, Dion M, Tailly T, Denstedt JD, Razvi H. Percutaneous nephrolithotomy in patients with urinary tract abnormalities.J Endourol. 2014;28(12):1448-54. [PubMed]

6. Skolarikos A, de la Rosette JJ. Prevention and treatment of complications following percutaneous nephrolithotomy. Curr Opin Urol. 2008; 18: 229-34.[PubMed]

7. Seitz C, Desai M, Häcker A, Hakenberg OW, Liatsikos E, Nagele U, et al. Incidence, prevention, and management of complications following percutaneous nephrolitholapaxy. Eur Urol. 2012;61:146-158.[PubMed]

8. de la Rosette J, Assimos D, Desai M, Gutierrez J, Lingeman J, Scarpa R, et al. The Clinical Research Office of the Endourological Society percutaneous nephrolithotomy global study: indications, complications, and outcomes in 5803 patients. J Endourol. 2011;25(1):11-17.[PubMed]

9. Tefekli A, Ali Karadag M, Tepeler K, Sari E, Berberoglu Y, Baykal M, et al. Classification of percutaneous nephrolithotomy complications using the modified Clavien grading system: Looking for a standard. Eur Urol. 2008;53:184-190.[PubMed]

10. Michel MS, Trojan L, Rassweiler JJ. Complications in percutaneous nephrolithotomy. Eur Urol. 2007;51:899906.[PubMed]

11. Dindo D, Demartines N, Clavien PA. Classification of surgical complications: A new proposal with evaluation in a cohort of 6336 patients and results of a survey. Ann Surg. 2004;240:205-213.[PubMed]

12. Zuazu JR, Hruza M, Rassweiler JJ, de la Rosette JJ. The Clavien classification system to optimize the documentation of PCNL morbidity. Arch Ital Urol Androl. 2010;82:20-22.[PubMed]

13. de la Rosette JJ, Opondo D, Daels FP, Giusti G, Serrano A, Kandasami SV, et al. Categorisation of complications and validation of the Clavien score for percutaneous nephrolithotomy. Eur Urol. 2012;62:246-255.[PubMed]

14. Violette PD, Denstedt JD. Standardizing the reporting of percutaneous nephrolithotomy complications. Indian J Urol. 2014;30:84-91[PubMed]

15. Tefekli A, Kurtoglu H, Tepeler K, Karadag MA, Kandirali E, Sari E, et al. Does the metabolic syndrome or its components affect the outcome of percutaneous nephrolithotomy? J Endourol. 2008;22:35-40.[PubMed]

16. Hu H, LuY, Cui L, Zhang J, Zhao Z, Qin B, et al. Impact of previous open renal surgery on the outcomes of subsequent percutaneous nephrolithotomy: a meta-analysis. BMJ Open. 2016 28;6(4):e010627.[PubMed]

17. Khorrami M, Hadi M, Sichani MM, Nourimahdavi K, Yazdani M, Alizadeh F, et al. Percutaneous nephrolithotomy success rate and complications in patients with previous open stone surgery. Urol J. 2014;11:1557-62[PubMed]

18. Hegarty NJ, Desai MM. Percutaneous nephrolithotomy requiring multiple tracts: comparison of morbidity with single-tract procedures.J Endourol. 2006;20(10):753-60. [PubMed]

19. Sugihara $T$, Yasunaga $H$, Horiguchi $H$, Fujimura $T$, Nishimatsu H, Kume $\mathrm{H}$ et al. Longer operative time is associated with higher risk of severe complications after percutaneous nephrolithotomy: analysis of 1511 cases from a Japanese nationwide database. Int J Urol. 2013; 20(12):1193-8.[PubMed]

20. Anastasiadis A, Onal B, Modi P, Turna B, Duvdevani M, Timoney A, et al. Impact of stone density on outcomes in percutaneous nephrolithotomy (PCNL): an analysis of the Clinical Research Office of the Endourological Society (CROES) PCNL global study database. Scand J Urol 2013;47(6):509-514.[PubMed] 